\title{
Plant polyphenols: are they the new magic bullet?
}

\author{
Garry G. Duthie*, Peter T. Gardner and Janet A. M. Kyle \\ Rowett Research Institute, Aberdeen AB21 9SB, UK
}

\begin{abstract}
Epidemiological evidence suggests that diets rich in fruit and vegetables decrease the risk of premature mortality from major clinical conditions, including cancer and heart disease. However, it is not yet clear which components or combination of components in fruit and vegetables are protective and what is their mechanism of action. Such scientific uncertainty does not seem to inhibit the marketing of a huge range of plant-based concoctions, promoted as 'magic bullets' for optimum health. For example, the purported health-giving properties of plant polyphenols represent a case in which enthusiastic marketing claims may far exceed the current scientific evidence. Even when good experimental evidence exists, results need to be interpreted with caution in relation to human health benefits, as polyphenols may have limited bioavailability and may also be extensively metabolised. In addition, some polyphenols can be toxic and mutagenic in some cell culture systems. Until more is known about the activity and metabolic fate of polyphenols in the body, it would be better for the consumer to increase fruit and vegetable intake, and also to be wary of claims that these compounds are a panacea for good health.
\end{abstract}

Polyphenols: Cancer: Heart disease: Bioavailability: Health claims

Human life expectancy continues to increase, so that in many countries middle age can be thought of as extending into the sixth or seventh decade of life (see Lutz et al. 1997). Paradoxically, as a result of living longer, there has been a relative increase in diseases that tend to appear later in life. Circulatory diseases and cancers now account for $>66 \%$ of the causes of mortality in countries with a high per capita gross national product, and the probability of suffering from these conditions increases exponentially with age. For example, cancer accounts for $>60 \%$ of deaths in males aged between 55 and 64 years, but only $10 \%$ in men $<35$ years (World Health Organization, 1998). Considerable epidemiological evidence suggests that habitual consumption of diets rich in fruit and vegetables decreases the risk of developing such conditions (Williams, 1995), and that the mantra of 'five servings of fruit and vegetables each day' may well be good advice. As yet, it is not clear which components of plant-based foods are protective and what is their mechanism of action. Potentially protective effects have been ascribed to numerous phytochemicals, including folate, vitamins $\mathrm{C}$ and $\mathrm{E}$, various carotenoids, Se, phyto-oestrogens and isothiocyanates. Despite this current scientific uncertainty, a huge range of products containing a myriad of phytochemicals are commercially available and marketed to convince the consumer that the holy grail of maintaining health can be achieved by the simple expedient of consuming such 'magic bullets'. Recently, much attention has focused on the possibility that polyphenolic products of the phenylpropanoid biosynthetic pathway in plants could also have a putative role in the prevention of chronic diseases. In addition to the widespread availability of polyphenol-rich extracts and supplements from commercial outlets, the presence of polyphenols in brands of generic products such as tea, wines, chocolates and soft drinks is also used to imply potential health benefits. While there is substantial evidence in vitro that polyphenols can influence numerous cellular processes that are potentially anti-carcinogenic and atherogenic, little is known about their bioavailability and metabolic fate. Consequently, it is unclear whether such analogous effects occur in vivo following consumption of polyphenol-rich foods. The aim of the present brief article is to consider whether the 'message' concerning the potential health benefits of polyphenols is being communicated appropriately, or whether enthusiastic marketing currently exceeds the current scientific evidence.

\section{What are plant polyphenols?}

Plants produce thousands of phenolic and polyphenolic compounds as secondary metabolites. They are essential to 
the physiology of plants, being involved in diverse functions such as lignification and structure, pigmentation, pollination, allelopathy, pathogen and predator resistance, and growth (Haslam, 1998). The majority are synthesised by the highlybranched phenylpropanoid pathway, which is responsible for the biogenesis of a large number of compounds of considerable structural diversity. However, most research to date on possible health benefits of polyphenols has focused on the flavonoids that have a common $\mathrm{C}_{6}-\mathrm{C}_{3}-\mathrm{C}_{6}$ structure consisting of two aromatic rings linked through an oxygenated heterocycle. Approximately 8000 have been described to date (Harborne, 1994), major classes being flavonols, flavones, flavan-3-ols, flavanones and anthocyanins (Table 1). Moreover, there are numerous structural variations within these major flavonoid classes that can be found in a single food item, and which depend on the level of hydrogenation, hydroxylation, methylation and sulfation of the molecules. In addition, most flavonoids form complexes with sugars, lipids, amines and carboxylic and organic acids (Harborne, 1994). For example, flavonoids are infrequently linked to galacturonic acid, but complexes with glucose, galactose and rhamnose are widespread (Fig. 1). This immense diversity of form makes it difficult to determine dietary intakes accurately. Estimation can also be confounded by differences in concentrations of many orders of magnitude between similar food items, because of the influence of several factors, including species, variety, light, the extent of ripeness, processing and storage (Peterson \& Dwyer, 1998). In general, however, dietary intakes of several flavonols and flavones are quantitatively similar to

Table 1. Some common dietary flavonoids indicating major food sources

\begin{tabular}{llc}
\hline Flavonoid & Subclass & Common food source (total flavonoid subclass content; mg/kg) \\
\hline Flavonols & $\begin{array}{l}\text { Quercetin }\left(\mathrm{R}_{1} \mathrm{OH}, \mathrm{R}_{2} \mathrm{H}\right) \\
\text { Kaempferol }\left(\mathrm{R}_{1}, \mathrm{R}_{2} \mathrm{H}\right)\end{array}$ & $\begin{array}{c}\text { Fruit: apples 34, plums 12, cranberries 170, strawberries 39, } \\
\text { grapes 31 } \\
\text { Myricetin }\left(\mathrm{R}_{1}, \mathrm{R}_{2} \mathrm{OH}\right)\end{array}$ \\
$\begin{array}{c}\text { Vegetables: kale 35-321, onions 0.2-1096, broccoli 36-231, } \\
\text { tomatoes 3-191 } \\
\text { Beverages: red wine 13 mg/l, green tea 39 mg/l, black tea } \\
30 \text { mg/l, grape juice } 4 \mathrm{mg} / \mathrm{l}\end{array}$
\end{tabular}

Flavones<smiles>Cc1cc(-c2cc(=O)c3c(Cl)cc(Br)cc3o2)cc(N)c1C</smiles>

Favan-3-ols<smiles>Cc1cc(C2Oc3cc(O)cc(Cl)c3CC2C)cc(Cl)c1C</smiles>

Flavanones<smiles>[R]Cc1ccc2c(c1)Oc1cc([R3])c([R9])c([R3])c1[C@@H]2[R]</smiles>

Anthocyanins
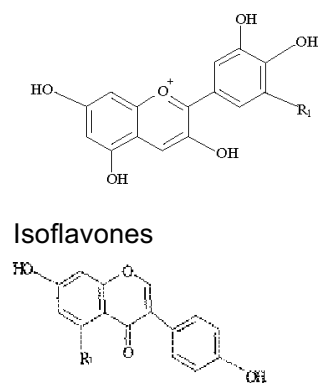

Apigenin $\left(\mathrm{R}_{1}, \mathrm{R}_{2} \mathrm{H}\right)$

Luteolin $\left(\mathrm{R}_{1} \mathrm{OH}, \mathrm{R}_{2} \mathrm{H}\right)$

Catechin $\left(\mathrm{R}_{1} \mathrm{H}, \mathrm{R}_{2} \mathrm{OH}\right)$

Epigallocatechin $\left(\mathrm{R}_{1} \mathrm{OH}, \mathrm{R}_{2} \mathrm{OH}\right)$

Epigallocatechin gallate $\left(\mathrm{R}_{1} \mathrm{OH}, \mathrm{R}_{2}-\mathrm{OC}-\mathrm{Ph}(\mathrm{OH})_{3}\right)$

Hesperetin $\left(\mathrm{R}_{1}, \mathrm{R}_{2} \mathrm{OH} ; \mathrm{R}_{3}, \mathrm{R}_{4}, \mathrm{R}_{5} \mathrm{H}\right)$

Naringenin $\left(R_{2}, R_{5} O H ; R_{1}, R_{3}, R_{4} H\right)$

Cyanidnin $\left(\mathrm{R}_{1} \mathrm{OH}\right)$

Delphinidin $\left(\mathrm{R}_{1} \mathrm{H}\right)$

Genistein $\left(\mathrm{R}_{1} \mathrm{OH}\right)$

Daidzein $\left(R_{1} H\right)$
Vegetables: celery 130, green olives 142, sweet peppers 11

Fruit: apples 84, plums 23

Beverages: green tea, black tea, red wine 110 , grape juice $5 \mathrm{mg} / \mathrm{l}$
Fruit: citrus fruits: oranges 577, lemons 219

Beverages: grape juice $2 \mathrm{mg} / \mathrm{l}$

Fruit: black grapes 92

Beverages: red wine $2 \mathrm{mg} / \mathrm{l}$, grape juice $2 \mathrm{mg} / \mathrm{l}$

$\mathrm{Ph}$, phenol. 
those of many well-recognised micronutrients, such as vitamin $\mathrm{E}$ and vitamin $\mathrm{C}$. For example, daily intakes in Scotland amount to approximately $100 \mathrm{mg} / \mathrm{d}$ (Table 2).

\section{In vitro evidence for beneficial effects}

Prospective studies relating estimated intakes or plasma concentrations of flavonoids to cancer and heart disease have given contradictory results (Knekt et al. 2002). In contrast, numerous in vitro studies indicate that plant polyphenols can potentially affect diverse processes in mammalian cells that, if also occurring in vivo, could have anti-carcinogenic and anti-atherogenic implications. These processes include gene expression, apoptosis, platelet aggregation, blood vessel dilation, intercellular signalling, P-glycoprotein activation and the modulation of enzyme activities associated with carcinogen activation and detoxification (for review, see Duthie et al. 2000). However, most marketing strategies tend to focus on the ability of many polyphenols to act as antioxidants. This approach is possibly unsurprising, as there is a substantial body of epidemiological and experimental literature suggesting that inadequate intakes of recognised nutritional antioxidants such as vitamin $\mathrm{E}$, vitamin $\mathrm{C}$ and carotenoids can lead to oxidative damage of proteins, lipids and DNA in vivo. This outcome, in turn, may predispose the development of many chronic diseases (Diplock et al. 1998).

\section{Antioxidant effects}

The antioxidant effectiveness of many polyphenols in vitro is essentially a result of the ease with which a $\mathrm{H}$ atom from an aromatic hydroxyl group is donated to a free radical and the ability of the aromatic structure to support an unpaired electron due to delocalisation around the $\pi$-electron system.

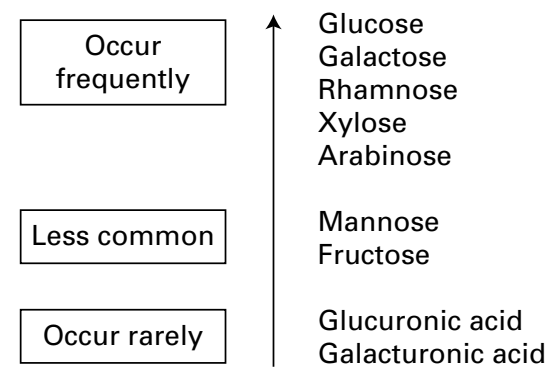

Fig. 1. Types of glycosidic linkages found with flavonols and flavones, ranked according to the frequency of their occurrence in plants.

Table 2. Estimated daily intakes of flavonoids, vitamin $E$ and vitamin $C$ in north east Scotland*

\begin{tabular}{lccc}
\hline Flavonoid & Median $(\mathrm{mg})$ & Minimum $(\mathrm{mg})$ & Maximum $(\mathrm{mg})$ \\
\hline Flavonols & 19 & 2 & 51 \\
Flavones & $0 \cdot 1$ & 0 & 7 \\
Procyanidins & 23 & 0 & 145 \\
Catechins & 59 & 2 & 263 \\
Flavanones & 1 & 0 & 239 \\
Vitamin E & 8 & 5 & 11 \\
Vitamin C & 65 & 37 & 108
\end{tabular}

*Data obtained from $4 \mathrm{~d}$ weighed intakes $(n 81)$.
For example, using stopped-flow electron-spin-resonance spectrometry methodology to assess the stoichiometry of the process of $\mathrm{H}$-atom transfer between polyphenols and synthetic radicals (Gardner et al. 1997), it is clear that many polyphenols can undergo multiple $\mathrm{H}$-atom or electron transfer steps. Moreover, antioxidant abilities of several polyphenols commonly found in the diet are comparable with those of vitamin $\mathrm{E}$ and vitamin $\mathrm{C}$ in organic (Table 3) and aqueous (Table 4) environments respectively. Whether such polyphenols have antioxidant effectiveness in vivo that is comparable with these recognised nutritional antioxidants is not clear. To be effective nutritional antioxidants such

Table 3. Comparison of antioxidant capacity of ethanolic solutions of flavonoids and vitamin $\mathrm{E}$

\begin{tabular}{lc}
\hline Compound & Lipophilic antioxidant capacity* \\
\hline Kaempferol & $1 \cdot 84$ \\
Quercetin & $3 \cdot 27$ \\
Tamarixetin & $1 \cdot 14$ \\
Taxifolin & $2 \cdot 82$ \\
Rutin & $3 \cdot 18$ \\
Datiscetin & $1 \cdot 74$ \\
Luteolin & $3 \cdot 24$ \\
Galangin & $1 \cdot 01$ \\
(+)-Catechin & $2 \cdot 96$ \\
Fisetin & $3 \cdot 68$ \\
Hesperetin & $0 \cdot 20$ \\
Apigenin & $0 \cdot 04$ \\
Myricetin & $4 \cdot 08$ \\
Myricetin trimethyl ether & 1.06 \\
Myricitrin & 3.66 \\
Morin & 1.83 \\
( \pm -Catechin & 3.75 \\
(-)-Epicatechin & $3 \cdot 83$ \\
Epigallocatechin & 3.49 \\
Epicatechin gallate & $8 \cdot 47$ \\
Epigallocatechin gallate & $9 \cdot 64$ \\
Vitamin E & $2 \cdot 14$ \\
\hline *Values are expressed as the no. of radicals reduced per mg. The antioxidant \\
capacities were determined from the ability of the compounds to reduce the \\
galvinoxyl radical using electron spin resonance spectroscopy. For details of \\
method, see Gardner et al. (1997).
\end{tabular}

Table 4. Comparison of antioxidant capacity of water-soluble flavonoids and vitamin C

\begin{tabular}{lc}
\hline Compound & Hydrophilic antioxidant capacity* \\
\hline Quercetin & 1.18 \\
Rutin & 0.89 \\
Myricetin & 2.24 \\
Myricitrin & 1.88 \\
$( \pm)$-Catechin & 2.56 \\
$(-)$-Epicatechin & 2.96 \\
Epigallocatechin & 2.73 \\
Epicatechin gallate & 3.64 \\
Epigallocatechin gallate & 4.35 \\
Vitamin C & 2.48
\end{tabular}

*Values are expressed as the no. of radicals reduced per mg. The antioxidant capacities were determined from the ability of solutions of the compounds to reduce Fremy's salt using electron spin resonance spectroscopy. For details of method, see Gardner et al. (1997). 
compounds need to be readily absorbed and transported to the relevant site within the cell for optimum function. In addition, they should not promote adverse reactions in the cell. However, as yet, little is known about the bioavailability and metabolic fate of polyphenols. Consequently, the disparity between the epidemiological studies and in vitro data may reflect, in part, relatively poor bioavailability and rapid metabolism and excretion of such compounds when ingested. For example, within $60 \mathrm{~min}$ of rats consuming $\left[2-{ }^{14} \mathrm{C}\right]$ quercetin- $4^{\prime}$-glucoside in a dose equivalent to a $70 \mathrm{~kg}$ human subject consuming $250 \mathrm{~g}$ onions, nineteen deglycosylated, glucuronidated, sulfated and methylated metabolites were detected in non-intestinal tissues, traces of the original compound being only found in the small intestine, where extensive glucuronidation had also occurred (Mullen et al. 2003). Moreover, those polyphenols with more potent antioxidant activity in vitro may be the most extensively metabolised in vivo compared with those with less oxidisable arrangements of the hydroxyl groups on the ring structures (Rice-Evans, 2001).

\section{Bioavailability and metabolism}

The absorption characteristics and subsequent metabolic fate of a polyphenol will probably depend on its individual structure. In general, however, studies to date suggest that 75-99\% of the ingested polyphenols are not detected in urine, which implies they have not been absorbed through the gut barrier, absorbed and excreted in the bile or metabolised by the colonic microflora or by the tissues. In addition, saturation of metabolic pathways by 'pharmacological' doses appears to be required to obtain the free form in the blood (Scalbert \& Williamson, 2000). Ingestion of nutritionally-relevant amounts results in extensive deglycosylation, glucuronidation, sulfation and methylation reactions mediated by a range of enzymes in the small intestine, liver and colon. These reactions include cytosolic $\beta$-glucosidases (small intestine, liver), lactase phlorozin hydrolase (small intestine), UDP-glucuronosyltransferases (intestine, liver), sulfotransferases (e.g. colon) and catecholO-methyltransferases (liver; see Scalbert \& Williamson, 2000; Williamson et al. 2000; Rice-Evans, 2001). Such extensive metabolism is characteristic of the body's way of dealing with a potentially-toxic insult, and may be a reflection of one of the roles of polyphenols in plants, which is to discourage attack by fungal parasites, herbivorous grazers and pathogens. This explanation is also supported by the many studies that indicate mutagenic, genotoxic and clastogenic responses of cell cultures to certain polyphenols such as quercetin (Brusick, 1993). On the other hand, there is very little evidence to date to suggest that dietary polyphenols promote adverse metabolic reactions in vivo when consumed in nutritionally-relevant quantities. However, as yet there is little clear evidence that polyphenols are putative dietary factors with important health benefits.

\section{Conclusion}

A deficiency in polyphenols does not cause any known clinical condition, unlike, for example, severe vitamin $\mathrm{C}$ deficiency causing scurvy and combined vitamin E and Se deficiencies resulting in myopathies and neuropathies (Combs, 1992). Indeed, consumption of flavonoid-free diets by human volunteers has recently been reported to lead to a decrease in markers of oxidative stress commonly associated with enhanced disease risk (Young et al. 2002). These authors speculate that this effect may be a response to a decrease in the intake of phytochemicals with potentially pro-oxidant effects. Until more is known about the mechanisms by which polyphenols are absorbed and metabolised, and the effects of the resulting conjugates and metabolites on cellular processes, it seems intuitively unwise to increase intakes by supplementation or food fortification or to promote them as a 'magic bullet'. This view is particularly apposite considering the unexpected adverse effects that were apparent in recent intervention trials with supplements of some of the well-recognised antioxidant nutrients (Omenn et al. 1996; Rapola et al. 1997).

\section{Acknowledgements}

Financial support from the Scottish Executive Environment and Rural Affairs Department, the EU (QLRT-199900124) and BASF, Ludvigshafen, Germany is gratefully acknowledged.

\section{References}

Brusick D (1993) Genotoxicity of phenolic antioxidants. Toxicology and Industrial Health 9, 223-230.

Combs GF (1992) The Vitamins. Fundamental Aspects in Nutrition and Health. London: Academic Press Inc.

Diplock AT, Charleux JL, Crozier-Willi G, Kok FJ, Rice-Evans C, Roberfroid M, Stahl W \& Vina-Ribes J (1998) Functional food science and defence against reactive oxidative species. British Journal of Nutrition 80, Suppl. 1, S77-S112.

Duthie GG, Duthie SJ \& Kyle JAM (2000) Plant polyphenols in cancer and heart disease: implications as nutritional antioxidants. Nutrition Research Reviews 13, 79-106.

Gardner PT, McPhail DB \& Duthie GG (1997) Electron spin resonance spectroscopic assessment of the antioxidant potential of teas in aqueous and organic media. Journal of the Science of Food and Agriculture 76, 257-262.

Harborne JB (1994) The Flavonoids: Advances in Research Since 1986. London: Chapman \& Hall.

Haslam E (1998) Practical Polyphenolics: From Structure to Molecular Recognition and Physiological Action. Cambridge: Cambridge University Press.

Knekt P, Kumpulainen J, Järvinen R, Rissanen H, Heliövaara M, Reunanen A, Hakulinen T \& Aromaa A (2002) Flavonoid intake and risk of chronic diseases. American Journal of Clinical Nutrition 76, 560-568.

Lutz W, Sanderson W \& Scherbov S (1997) Doubling of world population unlikely. Nature 387, 803-805.

Mullen W, Graf BA, Caldwell ST, Hartley RC, Duthie GG, Edwards CA, Lean MEJ \& Crozier A (2003) Determination of flavonol metabolites in plasma and tissues of rats by HPLC-radio-counting and tandem mass spectrometry following oral ingestion of $\left[2-{ }^{14} \mathrm{C}\right]$ quercetin- 4 '-glucoside. Journal of Agricultural and Food Chemistry 50, 6902-6909.

Omenn GS, Goodman GE \& Thornquist MD (1996) Effects of a combination of beta-carotene and vitamin A on lung cancer and cardiovascular disease. New England Journal of Medicine 334, 1150-1155. 
Peterson J \& Dwyer J (1998) Flavonoids: Dietary occurrence and biochemical activity. Nutrition Research 18, 1995-2018.

Rapola J, Virtamo J \& Ripatti S (1997) Randomised trial of alphatocopherol and beta-carotene supplements on incidence of major coronary events in men with previous myocardial infarction. Lancet 349, 1715-1720.

Rice-Evans C (2001) Flavonoid antioxidants. Current Medicinal Chemistry 8, 797-807.

Scalbert A \& Williamson G (2000) Dietary intake and bioavailability of polyphenols. Journal of Nutrition 130, 2073S-2085S.

Williams C (1995) Healthy eating: clarifying advice about fruit and vegetables. British Medical Journal 310, 1453-1455.
Williamson G, Day AJ, Plumb GW \& Coteau D (2000) Human metabolic pathways of dietary flavonoids and cinnamates. Biochemical Society Transactions 28, 16-22.

World Health Organization (1998) Life in the 21st Century - A Vision for All. Geneva: WHO.

Young JJF, Dragsted LO, Haraldsdóttir J, Daneshvar B, Kall MA, Loft S, Nilsson L, Nielsen SE, Mayer B, Skibsted LH, Huynh-Ba T, Hermetter H \& Sandström B (2002) Green tea extract affects markers of oxidative stress postprandially: lasting antioxidant effect of a flavonoid-free diet. British Journal of Nutrition 87, 343-355. 